\title{
Microbiological Profiling of Ice Cream Samples Sold in the Retail Shops in Dhaka City
}

\author{
Tasmina Rahman ${ }^{1 *}$, Bashudeb Chandra Sharma ${ }^{1}$ and Md. Niazul Isalm ${ }^{1}$ \\ ${ }^{1}$ Department of Microbiology, Stamford University Bangladesh, 51 Siddeswari Road, Dhaka-1217, Bangladesh.
}

\begin{abstract}
Being a popular ready-to-eat food among all age groups, ice creams warrant the maintenance of sound microbiological quality for the sake of public health safety. Present study investigated the microbiological quality of the commonly consumed ice creams available within the retail shops in Dhaka city, Bangladesh. Five ice creams from each comprising 3 types of samples (soft, hard \& flavored) of 7 most popular brands (a total of 90 samples) were collected and assessed for the presence of contaminating bacteria through conventional microbiological and biochemical identification methods. Total viable bacterial load was estimated within a range of $4.9 \times 10^{3}$ to $7.9 \times 10^{5} \mathrm{cfu} / \mathrm{ml}$. Brand $A$ ice cream samples were noticed to harbor the least amount of microorganisms. On the other hand $65 \%$ of samples belonging to brands $\mathrm{B}$ and $\mathrm{C}$ were found to be contaminated with Shigella spp. while $30 \%$ of samples of brand B and C and $60 \%$ of brand E were contaminated with $L$. monocytogenes. While some were found to be microbiologically sound, most of the ice cream samples studied were found to be contaminated with microorganisms. Maintenance of appropriate hygienic condition during manufacturing and storage of ice cream products are thus recommended to ensure the consumer health safety.
\end{abstract}

Keywords: Ice cream, microbial contamination, Listeria monocytogenes, total coliform, fecal coliform, consumer health safety.

\section{Introduction}

In Bangladesh where the summer is the longest season, varieties of ice creams serve as one of the excellent and popular ready-toeat food products among children and adults as well. Ice cream is known to be the frozen dairy product usually consisting of milk, cream milk, sugars, eggs, emulsifiers, stabilizers, flavoring agents, fruits, nuts, candies, syrups and other additives ${ }^{1}$. Even with an apparent nutritive image, ice creams have been often reported as the leading vehicle of microbial infection compared to the other dairy products such as cheese, sweets and yogurt ${ }^{2-3}$. The unfrozen or soft ice cream mix is indeed a sort of oil-in-water emulsion where the fat globules are dispersed and serves as a dispersion medium for proteins, sugars and salts in true solution thereby supporting the microbial growth and survival if contaminated ${ }^{3}$. Besides, the high milk content, the nearly neutral $\mathrm{pH}$ value and long storage duration may render the ice creams to be an excellent medium for microbial proliferation ${ }^{4}$.

The manufacturing process and raw materials used for ice cream preparation have been previously reported as the main sources of microbial contamination and thus deteriorate quality of ice cream $^{5}$. Primary sources of microbial contamination into ice creams include water and raw milk whereas the secondary sources of microbial contamination include the flavoring agents, utensils and the personnel associated with the processing and distribution. Sterilization method like pasteurization followed by freezing and hardening eliminate the most of pathogenic organisms; however, a handful of hazards can still retain in the finished products. Faulty manufacturing process, leakage in the processing tanks, post sterilization contamination, ill storage condition and low sanitary quality of packaging materials can contribute the admittance of pathogens into the products ${ }^{6}$. Many psychrophiles and psychrotolerant microorganisms like Listeria monocytogenes, Staphylococcus aureus, Bacillus spp., Salmonella spp., Shigella spp., Streptococus spp., Pseudomonas spp., Campylobacter spp., Brucella spp. and coliform bacteria are known to be the potential threats to ice cream quality ${ }^{7-8}$.

Almost all developed countries considered the establishment of ice cream industries as their prospective sectors public health improvement and economic enhancement; nevertheless, Bangladesh does not pose such improvisation in ice cream industries keeping the coherent consumer protection policies. Furthermore, Bangladesh does not have any organized and strict food control service to ensure the consumer safety; and it is often difficult to ensure the quality and hygiene of the ice cream products ${ }^{9}$. Along these lines, current study attempted e to assess the microbiological quality of the commonly consumed ice creams of reputed brands.

\section{Materials and Methods}

\section{Sources, Collection and Transport of samples}

This study was carried out in the Microbiology Laboratory of Stamford University Bangladesh. Ice cream samples from seven most popular manufactures (designated as Brand A, Brand B, 
Brand C, Brand D, Brand E, Brand F and Brand G) in Bangladesh were collected from retail shops. Three types of ice cream products were collected from each brand: hard (Lolly), soft (cup) and flavored (chocolate/strawberry). Five of each brand and of each type samples were collected aseptically from $-18{ }^{\circ} \mathrm{C}$ chambers at retail stores. Samples were checked for the valid expiry date and intact seal. All samples were transported to the laboratory within 15 minutes for sampling and subsequent studies.

\section{Preparation and processing of samples}

As per recommendation of Harrigan and McCance (1976) ${ }^{10}$ and Rahman (1997) ${ }^{11}$, ice cream samples were kept in water bath at 45 ${ }^{\circ} \mathrm{C}$ for thawing. After complete liquefaction of the ice cream samples, the top part of ice cream packages were opened. An aliquot of $50 \mathrm{ml}$ of ice cream sample was collected for each case using sterile glass pipette and transferred into a sterile conical flask. Afterward an exact quantity of $1 \mathrm{ml}$ of ice cream was pipette out aseptically and mixed with $9 \mathrm{ml}$ normal saline to get the $10^{-1}$ dilution. Further dilutions up to $10^{-6}$ were prepared for the microbiological analysis ${ }^{12}$.

\section{Enumeration of total viable bacteria and coliforms}

An aliquot of $0.1 \mathrm{ml}$ of each dilution was transferred and spread onto the nutrient agar, followed by incubation at $37^{\circ} \mathrm{C}$ for 24 hours. Plates exhibiting 30-300 colonies were counted. The average number of colonies in a particular dilution was multiplied by the dilution factor to obtain the total viable count (TVC) ${ }^{13}$. For the enumeration of coliforms, an aliquot of $0.1 \mathrm{ml}$ of each dilution was transferred onto the MacConkey agar. All plates were incubated at $37^{\circ} \mathrm{C}$ for 24 hours. On the other hand, for determining the load of the total fecal coliform, $0.1 \mathrm{ml}$ of each dilution was transferred onto the membrane fecal coliform ( $\mathrm{mFC}$ ) agar, followed by incubation at $44^{\circ} \mathrm{C}$ for 24 hours.

\section{Estimation of specific pathogens}

For the estimation of Staphylococcal load, an aliquot of $0.1 \mathrm{ml}$ of each dilution was transferred onto the mannitol salt agar (MSA), and incubated at $37^{\circ} \mathrm{C}$ for 24 hours. The total staphylococcal count was calculated according to ISO (1995) ${ }^{13}$. The results were expressed as the number of organism or colony forming units per mililiter ( $\mathrm{cfu} / \mathrm{mL}$ ) of ice cream sample.

For the detection of Shigella spp. and Salmonella spp. samples were enriched in selenite cysteine broth and enrichment was done in buffered peptone water at $37^{\circ} \mathrm{C}$ for 4 hours. For detection of Salmonella spp. and L. monocytogenes $0.1 \mathrm{~mL}$ sample was inoculated on the Salmonella-Shigella (SS) agar and Listeria selective supplemented Listeria agar, separately. Plates were incubated at $37^{\circ} \mathrm{C}$ for 24 hours. All the isolates were subjected to biochemical tests for further identification ${ }^{14}$.

\section{Results and Discussion}

As ice cream is a mouth watering and popular food, and the potent consumer group is especially the children. Hence this food item is supposed to be microbiologically safe ${ }^{8}$. As discussed earlier, the microbiological quality of ice cream samples are not satisfactory in many cases, the assessment of bacterial quality and presence of pathogenic strains is mandatory from public health perspective. A few studies have been conducted to assess the quality of ice cream in different cities of Bangladesh ${ }^{9,15}$ which reveals the poor quality of some ice cream samples. Consistently the present study also revealed a high burden of bacteria in most the samples studied (Table 1).

The heterotrophic bacteria were quantified within the range of $10^{3}$ to $10^{5} \mathrm{cfu} / \mathrm{ml}$ which were within the permitted limit $\left(10^{5} \mathrm{cfu} /\right.$ $\mathrm{mL}$ ) for consumption ${ }^{16-17}$. The hard type of ice cream of each of three brands harbored the lowest load of total coliform bacteria whereas the flavored type of ice cream showed the higher count. The coliform count was highest in Brand $\mathrm{E} \in \mathrm{ice}$ cream (73 cfu/ $\mathrm{mL}$ ) which was much higher compare to the standard which is $\leq$ $10 \mathrm{cfu} / \mathrm{mL}^{18-19}$. Brand $\mathrm{F}$ and $\mathrm{G}$ were free from coliforms. On the other hand, fecal coliform, which is always supposed to be completely absent in good quality ice cream, was detected in Brand C soft \& flavored type and Brand B flavored type ice cream. Brand A, F and $\mathrm{G}$ ice cream products exhibited the bacterial load within the acceptable limit, suggesting that Brand A ice cream products hold the superior quality among popular ice cream brands in Bangladesh.

The staphylococcal count was found to be variable among the brand and types of ice cream. However, Brand A possessed the lowest amount while Brand E B possessed the highest staphylococcal load. Staphylococcal species are widespread in the environment where the human nasal cavity and skin is the largest reservoir of this bacterium. From these sources, they are likely to be disseminated in the contacted air, dust and food products ${ }^{7}$. In certain circumstances, $S$. aureus is considered to be a source of enterotoxin and consequently an indicator of unhygienic condition, their presence reflects inferior quality of the tested product ${ }^{16}$.

Interestingly, the bacterial count in hard ice cream was found to be in the lowest quantity in every case (Table 1). It is assumed that the processing techniques, the acidic $\mathrm{pH}$ and temperature implicated in manufacturing of hard ice cream might prevent the bacterial access into the products. Although the ingredients used to produce soft and flavored type ice cream assumed to be the same, a significant bacterial load in the flavored ice cream was noticed probably due to the unhygienic processing means, the flavoring additives could have also introduced the contaminant bacteria into the samples. Among the specific bacterial pathogens, Shigella spp., Salmonella spp. and L. monocytogenes were noticed in the brands B, C and E ice cream samples, while brands A, D, F and G products were found to be completely free of these pathogenic bacteria (Table 2).

Even in the developed countries, the ice creams are usually found to be microbiologically competent, several studies in Asia Pacific region or in other developing countries on ice creams revealed the prevalence of a great number of bacteria often crossing the 
Table 1. Enumeration of total bacteria, total coliform, total fecal coliform and total staphylococcal count in tested samples

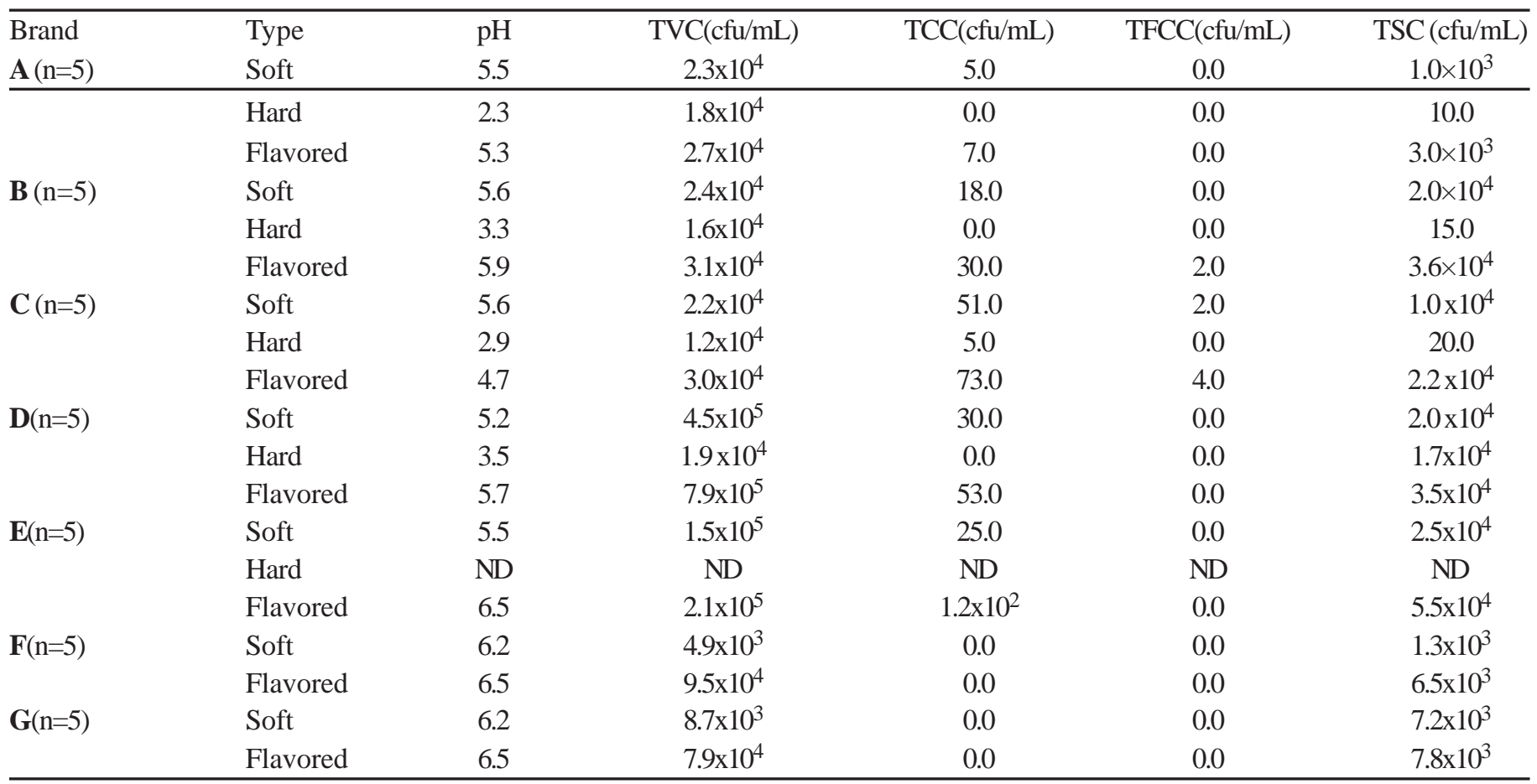

Note: TVC: Total Viable Count, TCC: Total Coliform Count, TFCC: Total Fecal Coliform Count, TSC: Total Staphylococcus Count, ND: Not done Average counts $(\mathrm{cfu} / \mathrm{mL})$ from all samples have been shown in this table.

Table 2. Detection of pathogenic bacteria on ice cream samples

\begin{tabular}{llcccc}
\hline Brand & Type & Presence of Shigella spp. & Presence of Salmonella spp. & Presence ofL. monocytogenes \\
\hline $\mathbf{A}(\mathrm{n}=5)$ & Soft & - & - & - \\
& Hard & - & - & - \\
& Flavored & - & - & - \\
$\mathbf{B}(\mathrm{n}=5)$ & Soft & + & - & + \\
& Hard & - & - & - \\
& Flavored & + & - & + \\
$\mathbf{C}(\mathrm{n}=5)$ & Soft & + & - & - \\
& Hard & - & - & - \\
& Flavored & + & - & - \\
$\mathbf{D}(\mathrm{n}=5)$ & Soft & - & - & - \\
& Hard & - & - & - \\
& Flavored & - & - & + \\
$\mathbf{E}(\mathrm{n}=5)$ & Soft & - & - & $\mathbf{N D}$ \\
& Hard & ND & $\mathbf{N D}$ & + \\
$\mathbf{F}(\mathrm{n}=5)$ & Flavored & Soft & - & - & - \\
$\mathbf{G}(\mathrm{n}=5)$ & Flavored & Soft & - & - & - \\
& Flavored & - & - & - \\
\hline
\end{tabular}

Note: +: positive, -: negative, ND: not done

recommended limit ${ }^{21-24}$. The findings of the current study is not indeed differing in some cases from those reports. A recent study by Akter and Ahmed ${ }^{25}$ revealed the presence of several pathogenic bacteria from two popular brands available in
Bangladesh. Comparing with this report, our findings reflect lesser degree of existence of pathogenic bacteria in ice creams collected from Dhaka city. However, suitable legislative actions are required to establish the safe manufacturing, processing and storage of 
the ice creams regularly consumed by mass people. An array of reay-to-eat food products in Bangladesh revealed huge contamination by microorganisms so far which can be fatal for the mass public health ${ }^{26}$. Regulatory actions on the prevention of microbial contamination of the ice cream products would be of health significance.

\section{Conclusion}

From the current investigation, it is evident that only one brand of ice cream products in Bangladesh offers good and standard quality products. Presence of pathogenic bacteria in other two popular brands reflects the likely unhygienic and unsanitary condition during processing, handling and distribution system. Proper training on good manufacturing practices (GMP) and use of the latest technologies in ice industries can reduce introduction of contaminants during ice cream production and establish the total quality management (TQM), and hence guarantee public health safety.

\section{Acknowledgements}

The work was supported by Department of Microbiology, Stamford University Bangladesh.

\section{References}

1. Diggins RV, Bundy CE and Christensen VW. 1984. Dairy Production, 8th Edn, pp 326. Prentice Hall Inc., New Jersey.

2. Bryan FL. 1984. Epidemiology of milk borne diseases. J Food Protect. 46: 637-649.

3. Ojokoh AO. 2006. Microbiological examination of ice cream sold in Akure. Pakis J Nutri. 5(6): 536-538.

4. Bigalke D and Chappel R. 1984. Ice cream microbiological quality. Controlling and other microbial contamination in ice cream. Dairy Food Sanit. 4: 318-319.

5. Hankin L and Hanna JG. 1984. Quality of ice cream and ice milk. Bull Connecticut Agric Exper Stat. 818: 6.

6. Joshi DR, Shah PK, Manandhar S, Sharma S and Banmali P. 2004. Microbial quality of ice cream sold in Kathmandu. J Nepal Heal Res Counc, 2(2): 37-40.

7. Jay JM. 1992. Modern Food Microbiology, Fourth edition. Chapman and Hall Inc. New York.

8. Warke RA, Kamat M and Kamat PJ. 2000. Incidence of pathogenic psychrotrophs in ice creams sold in some retail outlets in Mumbai. India Food Contr, 11: 77-83.

9. Hossain KMM, Kabir SML, Rahman MM, Rahman MB and Choudhury KA. 2012. Organoleptic and Microbial Quality of Ice Cream 94 Sold at Retail Stores in Mymensingh, Bangladesh. J Microbio Res. 2(4): 89-94.

10. Harrigan MF and McCance ME. 1976. Laboratory methods in food and dairy microbiology. Academic Press, London, England, pp 193.

11. Rahman MM. 1997. Practical food microbiology, pp. 70. Bangla Academy, Dhaka Bangladesh.

12. Graham T and Maturin L. 2004. Sampling Dairy and Related Products In: Standard Methods for the Examination of Dairy Products, $\mathrm{H}$. Michael Wehr and Joseph F. Frank, American Public Health Association.

13. ISO. 1995. Recommendation of the meeting of the subcommittee, International Organization for Standardization, on meat and meat products. ISO/TC-36/Sc-6. The Netherlands. 10-18.

14. Cappuccino J and Sherman N. 1996. Microbiology: a laboratory manual. San Francisco, CA: Benjamin Cummings.

15. Hossain MT and Kober AKMH. 2008. Microbiological Quality of Ice Cream Available in Chittagong. Bangladesh J Microbiol. 25(2): 135-136

16. Marion V. 1954. Maximum limits of bacterial count in ice cream. Ann. Sanita Pubbl. 13(4): 1075-1082.

17. USPHS. 1965. Standard method for examination of milk and dairy product. 11(2): 64

18. Frazier WC and Westhoff DC. 1958. Pasteurized milk in Milk Ordinance and Code, USPHS, Food Microbiology. 1st ed., pp. 112. Mc Graw-hill Inc.; New Delhi.

19. James M and Jay JM. 1978. Indices of Food Sanitary quality and microbiological standards and criteria. Modern Food Microbiology, 2nd ed. p. 311.

20. ICMSF (International Commission on Microbiological Specifications for Foods). 1998. Micro-organisms in Foods 6 - Microbial Ecology of Food Commodities. Blackie Academic and Professional London.

21. Food and environmental hygiene department. 2001. Micro-biological risk assessment of Ice-cream. Risk assessment studies report no. 7, Hong Kong.

22. Orallo GO, Pangan AH and Cabrera EC. 1999. Micro-biological analysis of ice cream produced by big scale and small scale manufactures in Metro Manila. Phil J Microbiol Infect Dis. 28: 99-101.

23. Azadnia P, Ghasemi MSA, Abbasi MR, Taarof N and Jashni MK. 2011. Microbial quality of traditional ice cream produced by small scale manufacturers in Khormoj and its comparison with the Iranian National Standard. J Ani Vet Adv. 10(6): 742-744.

24. Osamwonyi OU, Obayagbona ON and Olisaka F. 2011. Evaluation of the bacteriological quality of ice creams sold in some locations within Benin city. Continental J. Food Sci Tech. 5(3): 6 - 11.

25. Akter S and Ahmed S. 2012. Bacterial analysis of different types of ice creams from Dhaka city. Bangladesh J. Microbioli. 29(1): 41-43.

26. Sarker N, Islam S, Hasan M, Kabir F, Uddin MA and Noor R. 2013. Use of multiplex PCR assay for detection of diarrheagenic Escherichia coli in street vended food items. Am J Life Sci. 1 (6), 267-272. 